\title{
Voos literários com crianças indígenas e não indígenas na perspectiva intercultural, Campo Grande, MS
}

\section{Literary flights with indigenous and non indigenous children from an intercultural perspective, Campo Grande, MS}

\author{
Maria Elisa VILAMAIOR ${ }^{1}$ \\ Léia Teixeira LACERDA² \\ Maria Leda PINTO 3
}

\begin{abstract}
Resumo
Este artigo apresenta os resultados de uma pesquisa que buscou compreender como a leitura promove o interesse e o envolvimento de crianças de 4 a 5 anos, a partir das memórias leitoras de seus professores, a fim de contribuir para a formação desses leitores em relação aos valores humanos. Para tanto, apresentamos a análise das atividades de leitura mediadas pelos professores, por meio de poemas e desenhos, abordando o respeito às diferenças étnicas desses sujeitos, em uma perspectiva dos estudos da literatura infantil e da educação intercultural. Essa inter-relação oportunizou às crianças experiências interculturais de leitura no espaço escolar.
\end{abstract}

Palavras-chave: Aprendizagem da leitura. Educação Intercultural. Terena. Experiência de aprendizagem.

\begin{abstract}
This article presents the results of a research aiming at understanding how reading promotes the interest and engagement of 4- and 5-year-old children by means of their teachers' reading memories, in order to contribute to the formation of those readers regarding human values. Thus, we present the analysis of reading activities mediated by the teachers who used poems and drawings approaching the respect for the ethnic differences of those subjects, from a perspective that stresses studies of children's literature and intercultural education. That interrelationship provided intercultural reading experiences for the children in the school environment.
\end{abstract}

Keywords: Learning to read. Intercultural education. Terena. Learning experience.

1 Professora da Rede Municipal de Ensino de Campo Grande, Mestre em Educação pelo Programa de PósGraduação Stricto Sensu Mestrado Profissional em Educação da Unidade Universitária de Campo Grande da Universidade Estadual de Mato Grosso do Sul, Brasil. Membro do Grupo de Pesquisa: Educação Cultura e Diversidade, UEMS/CNPq (disponível em: <http://dgp.cnpq.br/dgp/espelhorh/0416559581832830>. Lattes: <http://lattes.cnpq.br/7184172529231354>. Acesso em: 28 jul. 2021). Orcid: <https://orcid.org/0000-00017751-8340>. E-mail: elisavilamaior@gmail.com

2 Docente do Curso de Pedagogia e do Programa de Pós-Graduação Stricto Sensu Mestrado Profissional em Educaçáo da Unidade Universitária de Campo Grande, Universidade Estadual de Mato Grosso do Sul, Brasil. Pesquisadora Associada do Centro de Pesquisa, Ensino e Extensão em Educação, Linguagem, Memória e identidade. Lattes: <http://lattes.cnpq.br/0416559581832830>. Orcid: <http://orcid. org/0000-0003-3752-0790>. E-mail: leia@uems.br

3 Docente Sênior do Programa de Pós-Graduação Stricto Sensu Mestrado em Letras e do Programa de Mestrado Profissional em Letras da Unidade Universitária de Campo Grande, Universidade Estadual de Mato Grosso do Sul, Brasil. Pesquisadora Associada do Centro de Pesquisa, Ensino e Extensão em Educação, Linguagem, Memória e identidade. Lattes: <http://lattes.cnpq.br/6631799224451076>. Orcid: <https://orcid.org/00000002-2826-7730>. E-mail: leda@uems.br 


\section{Considerações iniciais}

O estudo inerente às práticas de leitura na Educação Infantil atende à consolidação dos documentos legais dos sistemas escolares brasileiros e nos chama atenção quanto à orientação e à efetividade de práticas pedagógicas que sejam significativas para esse nível de ensino. Nesse processo, consideramos a vivência de leitura das crianças, em dois momentos - no núcleo familiar, espaço escolar mediado por seus pais, e na escola com seus professores e também por meio da interação com os colegas, que possibilitem seus primeiros voos literários.

A proposta investigativa apresentada neste artigo trata de uma pesquisa realizada com 5 professores de crianças de 4 a 5 anos de idade no campo da leitura. Esses profissionais atuam na Rede Pública de Ensino na Educação Infantil, na Escola Municipal Sulivan Silvestre Oliveira - Tumune Kalivono "Criança do Futuro", localizada no município de Campo Grande, em Mato Grosso do Sul, Brasil. A partir deste panorama temos como contexto, dados produzidos junto a uma professora identificada, pelas iniciais do seu nome, a fim de resguardar as condiçóes éticas. Além disso, temos a singularidade da comunidade que integra o espaço escolar composta por descendentes da etnia Terena e de não indígenas.

Consideramos a instituição como um palco promissor e abrangente para o estudo e as vivências interculturais e, nesse sentido, destacamos o potencial da leitura para o acesso ao conhecimento e o incentivo à formação de leitores da fase inicial das crianças ao longo do seu percurso escolar.

Assim, apresentamos os resultados de uma pesquisa intitulada Rodas de Leitura na Primeira Infância: formação de leitores e valores humanos em uma Escola Municipal de Campo Grande, MS, desenvolvida junto ao Programa de PósGraduação em Educação modalidade Stricto Sensu do Mestrado Profissional, em 2018, por meio das memórias leitoras de 2 professores terena e de 3 professores não indígenas. A partir do exercício desse olhar, "[...] tomamos o passado como algo ao qual devemos atribuir um sentido a nós mesmos" (LARROSA, 2015, p. 135), o que nos possibilita refletir sobre esse percurso literário e as implicaçóes na atuação pedagógica no que se refere à abordagem de atividades com crianças indígenas e não indígenas.

Para o desenvolvimento da pesquisa, registramos e analisamos os dados, por meio do Ateliê Biográfico de Projeto (doravante ABP). Essa metodologia possibilitou a análise das narrativas de experiências de leitura dos professores, considerando que "aprendizagens experienciais por meio de narrativas de formação servem de materiais para compreender o processo de formação, de conhecimento e de aprendizagem" (JOSSO, 1945, p.28-29) dos professores, tendo em vista que oportuniza reflexóes sobre suas memórias de leitura no percurso formativo educacional. 
Destacamos, também, a abordagem da metodologia do Projeto Entre na Roda, fomentado pela Fundação Volkswagen, que elucida a elaboração de rodas de leitura de maneira criativa, implementada com acessórios que possam cativar o leitor a vivenciar e compreender a leitura. Além dessa dinâmica, utilizamos no ABP a obra Série Sentimentos, de Ariadne Cantú (2012), composta por dez poemas que versam sobre sentimentos e valores humanos, como: a pressa, a raiva, a vergonha, o medo, a paciência, a saudade, a fé, a felicidade, o amor e a ternura.

Os teóricos utilizados nesta proposta investigativa foram estudiosos da Literatura Infantil e da educação intercultural. Além disso, os questionários e a gravação do roteiro de conversas foram transcritos tendo como parâmetro as Normas de Transcrição do Projeto NURC, da Faculdade de Filosofia, Letras e Ciências Humanas da Universidade de São Paulo, coordenado pelo Prof. Dr. Dino Pretti.

Os resultados revelaram o envolvimento dos professores para conhecerem e implementarem a metodologia apresentada, bem como para compreenderem de que forma os poemas podem subsidiar a prática da leitura com enfoque nos valores e sentimentos. Esse envolvimento foi expressivo ao demonstrarem a utilização de acessórios e a exploração de ambientes variados por parte dos professores ao desenvolverem suas rodas de leitura. Nessa interação, identificamos o potencial de uma metodologia inventiva que possibilita o gosto pela leitura desde a Educação Infantil, além de sua contribuição para a sensibilização e para a valorização humana.

\section{Princípios legais na Educação Infantil}

A partir da contextualização histórica dos conceitos de criança e infância, hoje falamos de um lugar privilegiado, tendo em vista a consolidação da educação infantil na esfera legal por meio da elaboração de propostas que visam um trabalho pedagógico que qualifique as atividades desenvolvidas nesse nível de ensino. Nessa perspectiva, temos como aporte legal a Lei de Diretrizes e Bases da Educação Nacional, no 9.394/1996 (BRASIL,1996), o Referencial Curricular Nacional para a Educação Infantil (BRASIL, 2001), o Estatuto da Criança e do Adolescente (BRASIL, 1990), além das Diretrizes Curriculares Nacionais para a Educação Infantil (BRASIL, 2010) e pareceres cuja finalidade é estruturar a qualidade do ensino.

Em termos municipais, o Referencial Curricular da Secretaria Municipal de Educação de Campo Grande/MS (SEMED), fundamentado na Constituição Federativa do Brasil (BRASIL,1988) e com amparo nas demais legislaçóes, regulamenta que a proposta de trabalho escolar deve preconizar três componentes: 
identidade e autonomia; comunicação e representação e conhecimento do mundo fisico e social, considerando o desenvolvimento do ensino e da aprendizagem das crianças.

Portanto, dos componentes principais da proposta curricular da Educaçáo Infantil, emergem três aspectos importantes:

I- Éticos: da autonomia, da responsabilidade, da solidariedade e do respeito ao bem comum, ao meio ambiente $\mathrm{e}$ às diferentes culturas, identidades e singularidades.

II- Políticos: dos direitos de cidadania, do exercício da criticidade e do respeito à ordem democrática.

III-Estéticos: da sensibilidade, da criatividade, da ludicidade e da liberdade de expressão nas diferentes manifestaçôes artísticas e culturais (BRASIL, 2009, p.2).

De acordo com esses princípios, é possível constatar a amplitude da função institucional responsável pelo processo de aprendizagem das crianças, dada sua função sociopolítica e pedagógica. Portanto, as escolas devem fundamentar sua matriz curricular a partir dessa regulação e ajustar em seu projeto político pedagógico conceitos éticos, orientações que poderão empreender para que se inicie o diálogo com as crianças, bem como a possibilidade de exploração dessas reflexôes na proposta curricular para a educação infantil. Dessa maneira,

[...] náo se restringe aos espaços físicos e materiais, mas abrange também as relaçôes interpessoais, a atmosfera afetiva, os valores que se exprimem nas açóes e as experiências educativas, promotoras de desenvolvimento humano e que trazem consigo as regras de tolerância, respeito, responsabilidade e do prazer de estar em grupo (OLIVEIRA, et al, 2014, p.42).

Nesse sentido, evidencia-se o primor da experiência literária nessa fase, pois, entre o conjunto de atividades propostas, a leitura se insere como uma importante ferramenta para a aprendizagem e para a sensibilização, já que, com a aproximação de textos, ilustraçóes, fantasias e com o acesso ao mundo cultural, pressupomos um aprimoramento das vivências de mundo pelas crianças.

A Lei $n^{\circ} 11.645 / 2008$, por sua vez, marca o processo de reconhecimento legal da cultura, com a obrigatoriedade do ensino da história, da cultura africana, da cultura afro-brasileira e da cultura indígena nos currículos dos estabelecimentos de ensino público e privado no país. Com a inserção legal da valorização da cultura e dos saberes da população indígena, é necessário o redirecionamento das atividades escolares para a valorização da educação intercultural, que por sua vez, nos possibilita "[...] problematizar diferentes elementos de como hoje, em geral, 
concebemos nossas práticas educativas e sociais" (CANDAU, 2013, p. 154). A esse respeito, Souza (2017) acrescenta:

Os estudos culturais gradativamente ganham espaço acadêmico, sendo objeto de debate na contemporaneidade, pois marcam um discurso de caráter social e um comprometimento com a ação política de minorias étnicas, raciais, sociais, linguísticas e de gêneros, entre outras. (SOUZA, 2017, p.5).

Nesse sentido, destacamos a discussão sobre a valorização e o reconhecimento da educação intercultural, que não se restringe a uma invenção moderna, mas que defende os direitos educacionais de uma prática pedagógica que preze o respeito ao valor humano em sua complexidade cultural desde a educaçáo infantil.

Paralelamente à crescente mudança legal na escolaridade das crianças, incluímos o Estatuto da Criança e do Adolescente (BRASIL, 1990) que, por seu turno, consolidou o amparo legal às crianças quanto ao seu direito de estudar, de viver em liberdade e de serem respeitadas em sua dignidade. Segundo esse dispositivo legal, "[...] a criança e o adolescente têm direito à liberdade, ao respeito e à dignidade como pessoas humanas em processo de desenvolvimento e como sujeitos de direitos civis, humanos e sociais, garantidos na Constituição e nas leis" (BRASIL, 1996, p. 12).

Nessa perspectiva, direcionamos nosso olhar para os princípios éticos, com base nas primeiras referências educacionais da criança vinculadas ao núcleo familiar, cujas implicaçóes refletem para além do ambiente escolar, na perspectiva dos cuidados necessários para ampliar sua compreensão de mundo e para se inteirar sobre outros saberes.

Desde cedo, a criança pode experimentar pequenas noçóes de valores éticos no decorrer dos cuidados para a aprendizagem e da convivência social. Dessa forma, o espaço educativo representa um solo fértil para o desenvolvimento da criança, pois a organizaçáo de atividades para a Educação Infantil favorece a reflexão sobre valores humanos, como o respeito ao Outro e a solidariedade. Haja vista a responsabilidade escolar "[...] em formar cidadãos éticos, [...] a sala de aula é um espaço onde o exercício da cidadania torna-se possível" (SANTOS, 2012, p. 15). Nesse cenário, "[...] será possível reconhecer também a intenção de cultivar o respeito ao bem comum, tanto no espaço da instituição de educação quanto na comunidade, na relação com o outro, investindo na construção de referências para o reconhecimento e o respeito das singularidades" (OLIVEIRA et al, 2014, p.39).

Nesse processo, o Referencial Curricular da Secretaria Municipal de Educação de Campo Grande/MS (SEMED) considera que as crianças vão experimentando 
diversas atividades, permeadas por suas capacidades imaginativas e reinventando açóes orientadas por suas percepçóes, uma vez que:

[...] vivem de forma intensa suas experiências. Significam e dáo novo significado ao mundo à sua moda: correm e pulam; conversam e recontam histórias; leem e escrevem; contam, cantam e dançam; pintam e desenham, observam e experimentam, imitam e brincam com a sua fantasia; choram e riem; brigam e compartilham (CAMPO GRANDE, 2017, p. 62).

Assim, as crianças traduzem suas expressōes de forma plena e única pelo diálogo de múltiplas linguagens que manifestam seu potencial criativo, reproduzindo suas ideias e inventando novas situaçóes de forma elaborada, ora conflitivas, ora harmoniosas, externando diversos sentimentos nas relaçóes coletivas que promovem o amadurecimento nos aspectos físicos, cognitivos e sociais.

Para Oliveira et al (2014, p.48), "[...] nas Diretrizes Curriculares Nacionais para a Educação Infantil, o planejamento de um currículo de Educação Infantil deve ter como eixos norteadores a 'interação' e a 'brincadeira”' (grifos dos autores). Nesses componentes curriculares, é possível reconhecer a seriedade da ação do brincar e do interagir com o Outro, que, para ter sentido, não ocorrem de maneira isolada na vida das crianças. Dessa maneira, em todos os movimentos, as crianças exercitam sua capacidade comunicativa e aprendem sobre valores, ao brincarem de faz de conta, ao imitarem a ação do adulto e, principalmente, nas atividades lúdicas de leitura e de escrita.

\section{Aspecto histórico da literatura infantil}

Nos últimos tempos, temos direcionado, com mais frequência, nosso olhar para o fenômeno cultural da leitura na rotina escolar. Isso porque o convívio com livros, a apreciação da leitura infantil e a possibilidade de acesso da população brasileira, notadamente do público infantil, faz parte de um processo construído socialmente, decorrente de intensos movimentos na organização social brasileira.

[...] Se a literatura infantil europeia teve seu início às vésperas do século XVIII, quando em 1697, Charles Perrault publicou os célebres Contos da Mamãe Gansa, a literatura infantil brasileira só veio a surgir muito tempo depois, quase no século XX, muito embora ao longo do século XIX reponte, registrada aqui e ali, a notícia do aparecimento de uma ou outra obra destinada a crianças (LAJOLO; ZILBERMAN,1985, p. 23). 
Segundo a exposição das autoras, é possível afirmar que o Brasil apresentou um longo trajeto para desenvolver a sua literatura, tendo em vista à reestruturaçáo vivenciada pelo país no campo político, social e econômico. Com o tempo, “[...] decorrente dessa acelerada urbanização que se deu entre o fim do século XIX e o começo do século XX, o momento se torna propício ao aparecimento da literatura brasileira para a infância” (LAJOLO; ZILBERMAN, 1985, p. 25).

Diante de todas essas mudanças ocorreu um intenso crescimento populacional na área urbana e, consequentemente, o reconhecimento social da criança, tendo em vista que a sua representação e o seu espaço, até então, não existiam. Sobre esse cenário, em que ocorre a representação de infância, incide o surgimento da literatura infantil, possibilitando às crianças estabelecerem contato com os livros.

É possível observar - em paralelo ao desenvolvimento econômico do país e às aspiraçóes das classes predominantes da época - o destaque da burguesia no processo de disseminação cultural dos livros, sendo essa camada social a principal responsável pela circulação literária em diferentes espaços. Sobre essa evolução, Lajolo e Zilberman (1985) registram que os primeiros livros destinados às crianças surgiram entre o final do século XVII e início do século XVIII.

De acordo com as autoras, historicamente, antes de estar presente nos debates acadêmicos, a leitura atravessou diferentes fases para chegar às classes populares, principalmente às crianças, muito embora se evidencia na sociedade brasileira, uma visão unívoca sobre a relevância da leitura.

Além disso, a revolução da indústria afeta a organização de diferentes espaços públicos, principalmente na esfera cultural. Nessa dinâmica, considerando-se os interesses diversos da camada social predominante, destaca-se ainda "[...] a implantação da Imprensa Régia, que inicia, oficialmente em 1808, a atividade editorial no Brasil, e começam a publicar-se livros para crianças". (LAJOLO; ZILBERMAN, 1985, p. 23).

Essas reflexóes evidenciam, entre outros aspectos, a importância do trabalho de leitura em sala de aula com as crianças a partir das contribuições de Lajolo e Zilberman (1985). Entende-se, pois, que a valorização da leitura, tanto no ambiente familiar como no processo escolar inicial, na educação infantil, constitui-se em caminho possível para o aprendizado dessa prática, tendo em vista, por exemplo, que as histórias infantis, a roda de leitura, os livros e o ouvir histórias desenvolvem nas crianças o processo estético-formativo, a sensibilidade, a imaginação e as emoçóes, possibilitando o encantamento próprio da infância, como nos afirmam Pereira, Frazão e Santos (2012):

Ler é apoderar-se de um bem, que uma vez adquirido, jamais será perdido: o conhecimento. Mas, o que se faz necessário para que um indivíduo venha a se tornar um 
leitor ativo e detentor de conhecimentos? Não existe uma fórmula, mas certamente há caminhos que levam a tal fim, e sem dúvidas o principal caminho é a prática da leitura na infância. É praticar, com o devido apoio, da família e da escola, esta açáo libertadora, a leitura é o pontapé inicial para o sucesso intelectual de um indivíduo. (PEREIRA; FRAZÃO; SANTOS 2012, p. 02).

Segundo essa perspectiva, a escola deve propiciar o espaço, as oportunidades e o estimulo às práticas de leitura desde a Educação Infantil para que possamos formar leitores, além de superarmos os baixos índices de acesso à leitura nessa nova geração de leitores no país. Afinal, como afirmam Coelho e Machado (2015),

O hábito de leitura estimula a capacidade criadora, multiplica o vocabulário, simplifica a compreensão do que se lê, facilita a escrita, melhora a comunicação, amplia o conhecimento, acrescenta o senso crítico e ajuda na vida profissional. O contato com a leitura deve começar desde a tenra idade quando as crianças estão mais flexíveis com a curiosidade aguçada. (COELHO; MACHADO, 2015, p. 05).

Igualmente, a leitura do texto literário no espaço escolar, como proposto por este artigo, possibilita às crianças alçar novos voos que lhes oportunizem estabelecer uma convivência com os diferentes sujeitos e uma interação privilegiada com o mundo. No contexto da pesquisa, professores indígenas e não indígenas buscam histórias infantis que permitem essa interação com o mundo imaginário, com as emoçôes e produzam conhecimentos, haja vista que a leitura do texto literário favorece o desenvolvimento da expressividade, além do conhecimento e da comunicação. Em outras palavras, "[...] a literatura cria a partir da realidade, da experiência de um eu, um objeto verbal, visando dialogar com o espírito e a emoção de um outro" (BRANDĀO; MICHELETTI, 1997, p.23, grifos das autoras).

Diante dessas consideraçóes, é importante ressaltar que a escola deveria privilegiar, na educação infantil e nos anos iniciais do ensino fundamental, a leitura dos textos literários, já que a literatura infantil é fundamental para o desenvolvimento global das crianças e oportuniza, desde os primeiros anos escolares, as vivências do discurso estético, da sensibilidade, da beleza das palavras, da imaginação. Isso vai muito além da linguagem do cotidiano e estimula a capacidade criadora e libertadora, e também o papel do professor no desenvolvimento da leitura e na formação do leitor por meio do texto literário.

Desta perspectiva, na proposta deste texto, adotamos como referência a natureza pedagógica apresentada pelos eixos das Diretrizes Curriculares Nacionais 
para a Educação Infantil (DCNEI) e as experiências leitoras dos professores, que, articuladas entre si nas atividades do ABP, oportunizam o aprendizado sobre o mundo e constituem diferentes valores culturais que podem ser descobertos e interpretados pelo potencial do texto literário.

\section{Voos literários com crianças indígenas e não indígenas na educação infantil}

A história em si da população Terena, apresentada por meio de sua oralidade, inspira um convite para refletirmos sobre a ação mágica da leitura com crianças no início de sua escolaridade, o que parece promissor para a vivência da interculturalidade. Desse modo, consideramos a proposta do voo literário a ser vivenciado pelas crianças indígenas e não indígenas junto aos seus professores, na Escola Municipal Sulivan Silvestre Oliveira -Tumune Kalivono "Criança do Futuro", localizada na primeira aldeia fundada no município de Campo Grande, MS, em 1999.

Propusemos, assim, um voo no sentido imaginário com as experiências de leitura, a partir de uma metodologia criativa do projeto Entre na roda, apresentado pelo Cenpec - Educação, em parceria com a Fundação Volkswagen, que "[...] constitui uma proposta de incentivo e orientação à leitura, que visa o desenvolvimento tanto do gosto pela leitura como das capacidades leitoras" (CENPEC, 2011, p. 12). Além disso, fundamentamos a ação literária nos poemas que evidenciam dez sentimentos apresentados por Cantú (2012), a fim de refletirmos sobre a ideia da rejeição, do acolhimento e do respeito às diferenças.

A princípio, um dos professores participantes da pesquisa, propôs a realização de roda às crianças para orientá-las sobre a atividade de leitura. Nesse momento, o professor dialogou com elas a respeito da atividade e da oportunidade de viajarem ao entrarem no cenário da história; nessa ação, destacou-se a importância da postura para participarem dessas narrativas. Assim, foram consideradas três fases para o desenvolvimento literário: antes, durante e depois da leitura, fundamentadas nos estudos de Solé (1998), que contribuem com a ideia apresentada pelo projeto Entre na Roda ao sugerir dinâmicas de aquecimento, leitura e desdobramento da leitura.

Em seguida, as crianças foram conduzidas ao espaço externo da escola e acomodadas à sombra de um pé de abacateiro. $\mathrm{O}$ professor se preparou para narrar a história, recompondo a roda e, assim, o aquecimento para a leitura ocorreu com o convite a duas crianças para segurar a casa do fantoche. $\mathrm{O}$ docente saudou a turma em língua Terena, nakeyeye, e assumiu a suposta identidade de ser seu irmão gêmeo, perguntando: 
Quem adivinha o nome dessa história? Vocês conhecem essa história ou alguma semelhante a essa? Do que se trata? Hoje eu vim aqui e trouxe uma história bem legal para vocês, vamos escutar, quero que prestem atenção... Eu não vou falar o nome, são vocês que irão descobrir o nome da história e me dizer (PM, 2018).

O professor ilustrou a capa, evidenciou os personagens e as crianças sugeriram: "Patinho feio"; "Turma da Mônica...". O educador respondeu: "será que vai tratar do Patinho feio? Conhecem a história? O que isso tem a ver com a Turma da Mônica? E quais sentimentos existem entre eles?"

Nessa dinâmica, observamos a satisfação das crianças, que auxiliaram o professor, pois se sentiram valorizadas ao participarem da leitura, tocando nos personagens, como os patos e mesmo a casa do fantoche, além de se encantarem com o figurino, peruca e lenços, e com a maneira diferente de narrar a história, o que gerou o envolvimento da turma na atividade.

Com muita tranquilidade, narrou-se a história e, à medida que o professor folheava as páginas do livro, fazia alguns questionamentos sobre a suposta ação que viria a seguir, o que os pequenos suspeitavam que pudesse acontecer após a rejeição do pato considerado feio, entre outros. Além disso, ao observar algum momento de dispersão, sugeria que retornassem aos seus lugares e destacava a relação do pato com o cachorro, buscando garantir a escuta e a interação dos estudantes com a leitura.

Com base nesse registro, notamos que o professor, durante a leitura, narrou a história de forma interativa e foi perceptivo ao movimento e ao interesse dos estudantes. Para o desdobramento, perguntou: "o que aprenderam com a história? Qual foi a parte que mais gostaram? Aquele patinho que parecia feio está feio agora? Por que era chamado de patinho feio?". Concluiu-se com a reflexão de que, na verdade, o pato era um cisne, cresceu e se transformou, com penas brancas enormes e diferente dos patos amarelos. Assim, ressaltou-se a atitude entre os animais e o que o texto quer ensinar, pensando nos sentimentos bons e ruins, dependendo da maneira como convivemos com o Outro.

$\mathrm{Na}$ sequência da atividade, todos retornaram para a sala e as crianças foram orientadas a pensarem a partir da açáo dos personagens e sobre o que aprenderam com eles, enfatizando a invenção de uma história bonita e feliz. Ao final, as crianças constatam que o protagonista foi amado e respeitado em suas diferenças, demonstrando que todos podem brincar, amar, divertir-se, dar boas risadas e sentir felicidade no coração com amigos diferentes e que o carinho pode prevalecer.

$\mathrm{Na}$ história o patinho conviveu com a rejeição, jogado por outros animais. Agora vamos mostrar a família do 
patinho feliz, onde os animais vão querer ficar perto dele e aceitá-lo do jeito que ele é, lembrando de uma parte da história, que o cachorro levou para sua casa e lhe deu abrigo, lugar para dormir e não foi maltratado, como outros personagens fizeram ao rir e debochar dele (PM, 2018).

Identificamos, nessa experiência, a trama de ideias que se compôs, especialmente quando a criança é estimulada a criar e pensar sobre a história. Ora, o pato estava triste pelo estranhamento dos amigos a pela diferença de sua cor; depois, com a mudança da história, mostrou-se uma família acolhedora, protetora, fazendo bolo para cuidar de todos os filhos, um dentro da barriga e outros que já descobriram o mundo, ao lado do irmão e dos demais animais, com expressão de felicidade e união.

O texto promove ainda uma reflexão sobre sentimentos diversos que pautam o convívio humano, que podem, por exemplo, favorecer uma vida preenchida pela felicidade, abraçada pelo amor quando sentimos "[...] aquele calorzinho... Que a gente sente no fundo da barriga. E que nos faz sorrir para tudo" (CANTÚ, 2012, s.p.), como também a inquietação de sentimentos turvos, que dilaceram o coração quando são depreciados. Fica "[...] acinzentado [...] quando o coração fica...Todo encolhido...Apertadinho e sem ar. E de táo pequenininho... Parece que vai explodir! Tum-tum"(CANTÚ, 2012, s.p.).

Consideramos, nesse exercício, a inspiração das crianças em participarem da leitura e da produção de desenhos alinhada às estratégias pedagógicas do professor. A ação pode revelar o envolvimento do narrador da história, durante o processo vivenciado, ao realizar uma roda de leitura diferenciada e criativa, bem como nos participantes da leitura, pois tiveram a oportunidade de demonstrar sentimentos despertados pela mensagem do texto literário.

\section{Memórias leitoras de professores no Ateliê Biográfico de Projetos (ABP)}

Para o desenvolvimento da pesquisa, convidamos os 5 professores indígenas e não indígenas a narrarem suas memórias leitoras por meio da metodologia do ABP, concebida por Delory-Momberger. Essa abordagem revela o potencial do procedimento para a reflexáo do fazer pedagógico, tendo em vista a experiência de leitura no percurso formativo desses professores. Nessa perspectiva, esse caminhar possibilita 
a ação de elaborar, revisar, modificar, transformar uma maneira de estar no mundo, um complexo de relaçóes com os outros e consigo mesmo, é [...] formular um novo olhar sobre o seu passado e sobre suas origens, projetar ou sonhar um outro futuro, se biografar novamente. (DELORYMOMBERGER, 2006, p. 126).

Desse modo, apresentamos o desenvolvimento das rodas de leitura dos profissionais citados e, a partir dessa ação, foram analisadas as peculiaridades de suas percepçóes imaginárias para explorar o livro, considerando nesse percurso, a dinâmica da abordagem da leitura na metodologia do Projeto Entre na Roda e do ABP. Elegemos, para este artigo, a roda de leitura realizada pela professora PN; em seguida, apresentamos as estratégias utilizadas por ela durante a implementação da atividade, na perspectiva do projeto Entre na Roda, a fim de promover a compreensão dos poemas de Cantú (2012).

PN planejou suas ações após a acolhida do Pré-escolar II, no turno matutino. A educadora se inspirou no vídeo: Toda criança tem direitos, disponível no canal do Youtube, exibido durante os encontros do ABP. A mensagem do vídeo trata dos direitos fundamentais da criança, como saúde, educação, lazer, solidariedade, entre outros aspectos. As crianças assistiram e depois cantaram o refrão: "direitos da criança, vamos todos defender, se assim fizermos, um novo mundo vamos ter”. A partir dessas palavras-chave, a professora apresentou os poemas de Cantú (2012) e conversou com os estudantes sobre os dez sentimentos tratados pela autora, considerando as representaçóes que estavam agrupadas em três caixas.

Nessa abordagem, destacou os sentimentos de acolhimento e solidariedade para com as diferenças sociais com base na disseminação do amor. Este sentimento, por sua vez, pode afetar os demais, ensinando a conter emoçóes inquietaçóes, como a pressa, por exemplo, conforme narra a autora:

Um caminhão de cimento gigante, carregado de pensamentos atrasados que ficam girando... girando na cabeça da gente... É tomar banho rápido e esquecer-se de lavar atrás das orelhas. É ficar olhando a espuma descer pelo ralo enquanto... O tempo devora os minutos de algo importante que temos a fazer (CANTÚ, 2012, s.p.).

A escolha desse poema possibilitou o diálogo com as crianças sobre as vivências de novas emoçôes, motivada pelo pensar e o agir, além da repercussão da pressa, que impossibilita olhar o Outro na sua diferença e humanidade, com maiores detalhes. No que se refere às interaçóes estabelecidas entre as crianças, no processo de ensino e aprendizagem, a informação passa pelo olhar, considerando 
que pode ocorrer uma ausência de atenção suficiente para fazer uma atividade de maneira adequada, para atender o amigo, para chegar no horário, para estudar sem esquecer o material.

Ao abordar a qualidade de bons sentimentos, como o amor, na perspectiva da autora que assim o expressa "- oba! O maior de todos - o+ bonito - o mais brilhante... De todos os sentimentos” (CANTÚ, 2012, s.p.) - a professora PN dialoga com as crianças sobre o amor ser o propulsor dos demais sentimentos. Ele possibilita nos relacionarmos com as pessoas, como também brincar com amigos de maneira feliz, respeitando-os em suas características individuais. Nesse processo há pessoas que possuem agilidade para realizar açóes, construindo a aprendizagem juntos, vivenciando experiências de ternura e fé, ao acreditar na amizade e no companheirismo dos colegas da escola.

Com a proposta de oportunizar às crianças voos criativos para ensiná-los as habilidades de leitura, a princípio, a professora desenvolveu atividades de aquecimento, por meio de recurso audiovisual, iniciou a narração em sala de aula deslocando-se em seguida com os estudantes para a quadra esportiva da escola para dar continuidade à atividade. Para tanto, utilizou adereços como: peruca, tapete mágico, jaleco e suportes que possibilitassem sua expressáo de sentimentos, bem como a entonaçáo de sua voz para compor o cenário leitor.

Em seguida apresentou às crianças os questionamentos: "o que o vídeo sobre os direitos humanos nos fala? Os sentimentos de Cantú (2012) têm a ver com a viagem literária que faremos agora? Será que a história tem relação com isso? O que acham?" Assim, conseguiu provocar expectativas entre as crianças, que ficaram curiosas para saberem o que poderiam descobrir ao viajar no tapete mágico.

Diante das expectativas positivas das crianças a professora $\mathrm{PN}$ os acomodou no tapete e incorporou um motorista animado, que conduziria o transporte com a carroceria cheia de felicidades, ternura e amor. Logo, anunciou que ouviriam a história junto aos pássaros hospedados no teto da quadra e, assim, poderiam sentir que a felicidade "[...] é voar pra longe sem sair do lugar. É passear no parque de pés descalços. É sorrir de olho fechado” (CANTÚ, 2012, s.p.).

As crianças manifestaram ar de graça com risos e fizeram comentários sobre as aves que voavam no local: — "como vão ouvir?”, "Elas não são pessoas!","Vai, vai, motorista, funciona logo o motor do carro..." "queremos viajar", "socorro... já vai sair...". Nesse movimento, observamos que os estudantes foram fisgados pela magia da leitura, evidenciando que a "[...] a liberdade nos deixa muitas liçóes, pois é a liberdade de tomar a palavra. Por isso, a ação do texto é o texto por vir: a palavra do por-vir. Em virtude de nossa disposiçấo no que vem se dizendo ou no que vai ser dito" (LARROSA, 2015, p.145). Assim, esse é o movimento oportunizado pela leitura que contribui com a formação do leitor. 
Nas vozes e na feição das crianças, notava-se entusiasmo e risos, causados pelo uso dos acessórios utilizados pela mediadora leitora, durante a preparação, a realização e a exploração da história proposta. Também foi possível identificar as expectativas e a interlocução dos pequenos com o conteúdo abordado no texto.

A professora continuou indagando às crianças se é possível manifestar sentimentos contraditórios diante da felicidade - como, por exemplo, ao chorar - explicando que podemos chorar de tristeza e/ou de alegria, quando vivenciamos situaçóes que nos alegram ou nos desagradam. Isso porque, no coração, armazenamos bons sentimentos que podem provocar reaçôes distintas para cada pessoa.

Por meio dessa ação as crianças que não conseguem ler sozinhas podem, ainda assim, conhecer a beleza e a magia das palavras por meio dos adultos que leem para elas, que lhes emprestam voz. Ao ler para as crianças, o professor lhes garante o acesso a uma cultura que seria inacessível nessa época da vida, reservada apenas aos que devem aprender a ler e a escrever na escola (OLIVEIRA et al, 2014, p. 192).

Depois dessas motivaçóes a professora PN, apresentou a história Adivinha quanto eu te amo (BRATNEY, 2011), articulada aos poemas de Cantú (2012). O texto contextualiza a relação do papai coelho com seu filho, personagens que expressam a profundidade do amor mútuo e utilizam a capacidade imaginária e lúdica para externar a dimensão desse sentimento. $\mathrm{O}$ propósito dessa leitura foi verificar em que medida as crianças poderiam definir o tamanho dessa afetividade.

Essa dimensão parecia poder ser mensurada pelo "esticar dos braços", alcançada pelas "pontas dos dedos dos pés", entre um balançar e outro dos saltos e se deslocar de um pulo a outro, de ponta cabeça, em toda estradinha, após o rio, onde não havia limites geográficos, até alcançar a plenitude do céu para afirmar a certeza desse amor. Nesse sentido, compreendemos que a manifestaçáo de sentimentos ocorreu na relação entre pai e filho e, após a finalização da leitura, a professora explorou a narrativa e argumentou que pode ocorrer a descoberta e a reproduçáo desses sentimentos entre amigos, trazendo para a discussão o sentimento do amor para estabelecer uma conexão entre as crianças.

Analisamos, nessa dinâmica, que o deslocamento do cenário literário para o ambiente fora do contexto da sala de aula gerou expectativas diferenciadas, ao mesmo tempo envolventes e surpreendentes, expressas pelas reaçóes das crianças. Essas reaçóes aconteceram a partir da vestimenta (jaleco, perucas e caixas com a temática dos poemas), bem como pela maneira como a mediadora deu vida aos personagens, pois a entonação de sua voz fez toda a diferença para a compreensão dessa ação. 
Ademais, a todo instante, articulava-se a afetividade aos direitos humanos e à relevância de semearmos o amor, a ternura e a felicidade para atingirmos o Outro com respeito, sem distinção cultural e social, explorando o imaginário que a arte literária possibilita provocar. Assim, a docente organizou uma lista de informaçóes sobre emoçóes positivas na relação entre papai coelho e filho, extensivas à relação humana.

Para o desdobramento da história, PN, durante a viagem no tapete mágico, indagou:

Quem é que brinca nesse cenário? Eu tenho direito e as crianças têm o direito ao amor, ao respeito, a viverem juntos, a brincarem, têm direito a serem amigos, a respeitar e ser respeitadas. Ninguém bater, xingar, brigar. Que entre as crianças ocorrem a relação da boa convivência com os brancos, negros, indígenas, japoneses e que entre eles não há "pré-conceitos" (PN, 2018).

Ao problematizar a relaçáo de afeto entre papai coelho e seu filho, PN observou também que o amor entre eles pode ser ampliado entre os colegas, irmãos e nas demais relaçóes sociais com base no respeito. Para finalizar a leitura, sugeriu à turma pensar nas crianças que viram no vídeo, abraçadas ao planeta, para fazerem o mesmo com seus colegas, destacando que o respeito é fundamental entre todas as pessoas e que, na escola, convivem cotidianamente indígenas, negros, pardos, brancos e deficientes físicos. Defendeu ainda que essas diferenças devem ser reconhecidas e valorizadas para aprenderem juntas e, assim, contribuir com uma vida coletiva mais humana.

O direito de brincar nos jardins, nos espaços públicos e de todos terem amigos. Não importa a deficiência ou diferenças apresentadas, devem ser respeitadas com igualdade. Direito a viver bem, ter família, a ir ao médico. Olhem quantas crianças tem... cada uma delas tem uma família constituída por negros, indígenas, japoneses, brancos, pardos e podem ser felizes (PN, 2018).

A partir da palavra-chave - respeito - orientou o grupo a produzir desenhos que evidenciassem o que aprenderam sobre o sentimento do amor pelos amigos indígenas e não indígenas. Nessa atividade, a professora sugeriu o registro das ações, partilhadas coletivamente durante as brincadeiras, o manuseio dos brinquedos, durante os lanches, a contação de história, que podem fortalecer os laços de amizade e manifestar sentimentos afetivos, como foi demonstrado pelo coelhinho ao seu pai, bem como à família. Nessa interação, refletiu sobre a possibilidade de disseminar a paz, o amor, o acolhimento e o respeito ao Outro no espaço de convivência social. Destacamos, desse espaço, 5 das produçóes realizadas pelas crianças. 
Produçáo 1 - Retrata uma família feliz dentro de um coração, com a presença de seus familiares (pai, mãe, tios, avós e primos).

Produçáo 2 - Apresenta desenhos em forma de coraçóes da família e o cachorro de estimaçáo, além de 3 crianças, brincando de jogar bola com os amigos na quadra da escola, durante a aula de Educação Física.

Produçáo 3 - Ilustra o time de futebol com traves, goleiros e a bola. Além da equipe, desenhou 3 amigos no banco de reserva, aguardando para jogar. $\mathrm{Na}$ sequência, destacou o retrato de um casal de amiguinhos e o outro de irmáos que se amam, cercados de amor, simbolizado por meio de desenhos em forma de coraçóes.

Produçáo 4 - Ilustra, por meio de 2 coraçóes, o acolhimento da família indígena, bem como os brinquedos. Logo após, acrescentou um peixe e um móbile de coração e, para finalizar o desenho, amigos brincando no escorregador em um dia ensolarado no parque da escola.

Produçáo 5 - Retratou a interação entre três crianças no parque de areia da escola.Uma delas brincava com o cachorro e outras, irmâs, subiam e desciam do escorregador. Na sequência dos desenhos, ilustraram sua família, a moradia, a amor e a brincadeira de pular corda. Por último, retrataram a brincadeira de roda com uma nuvem de coraçôes na cabeça em que sobrevoavam borboletas e pássaros.

Analisamos, nesse processo, experiências relevantes para o conhecimento e para a aproximação das crianças com a leitura por meio da participação, do envolvimento e da produçáo autoral, como o resultado de seus desenhos. A professora, de acordo com a percepçáo de sentimentos, instigou-as a pensar sobre hipóteses de amor que vivenciam junto à família, na interação escolar e pelas preferências de suas brincadeiras, questionando-as: "o que mais gostam de fazer na escola? O que deixa vocês felizes? O que tinha de bonito na história dos coelhos? Era o amor!" (PN). Dessa forma, pode-se ampliar ideias e contribuir com os repertórios particulares dessas crianças, visando à qualidade na aprendizagem da leitura e, sobretudo, oportunizando com as práticas pedagógicas, experiências sobre o aspecto da interculturalidade ao sensibilizá-las sobre os sentimentos de acolhimento e da valorização dos sentimentos afetivos.

\section{Considerações finais}

Ao propormos a formação de jovens leitores interculturais na educação infantil, na perspectiva do dinamismo das rodas de leitura, elucidamos a relevância de uma prática pedagógica coerente no contexto educativo que compreenda as demandas legais sobre o mundo contemporâneo, que oportunize às crianças o acesso ao conhecimento de geraçóes e suas diferenças mediada pela ação da leitura. 
Nesse processo, "é importante o papel do professor para reconduzir informações e centrá-las no tema em questão” (SOLÉ, 1998, p. 107), o que está presente no conteúdo, o que os personagens revelam sobre o mundo, como se constitui a relação com outras pessoas, além das informaçóes que conhecem, a fim de problematizar e sensibilizá-las. "[...] De forma análoga, a leitura do outro faz com que se responda a ele emocionalmente com atitudes de repulsa, rejeição, desprezo, ódio, ou de admiração, respeito, confiança e tentativa de imitação" (THIÉL, 2013, p. 13).

Nessa interação, as crianças podem vivenciar amplas experiências de aprendizado sobre sentimentos, descobertas sobre culturas e conflitos, importantes para a compreensão sobre os valores humanos táo necessários ao convívio social em grupo. Desse ponto de vista, evidenciamos a valorização da leitura com as crianças e refletimos sobre os resultados significativos quando entram em contato com bons livros, participam de uma roda de leitura empreendida com entonação e criatividade, o que pode permitir à criança voos a diferentes países, a fim de conhecer as variaçóes culturais, regionais, os grupos étnico-raciais presentes em seu entorno.

A ideia da leitura intercultural que defendemos não restringe a função literária ao ensino de um conteúdo específico, mas pelo fenômeno em potencial que representa a formação das novas geraçôes de leitores. Compreendemos a leitura intercultural como uma fonte inesgotável de conhecimento, pois pode promover discussóes e descobertas sociais sobre a origem de si, do Outro e com isso interpretar o mundo.

Nesse sentido, identificamos o potencial da leitura para a formação do leitor intercultural, principalmente com crianças com base nas diferentes linguagens que dialogam entre si no cotidiano da educação infantil. Assim, evidenciamos o espaço de socialização dessas crianças e as múltiplas possibilidades de exploração de repertórios culturais quando se movimentam, brincam, desenham, cantam, leem e recontam suas histórias.

Desse modo, os resultados analisados na perspectiva do contexto escolar intercultural, onde ocorreu a pesquisa, evidenciaram que os professores refletiram sobre suas memórias leitoras e experiências pedagógicas com o ensino da leitura. Nesse exercício, destacamos a relevância de uma metodologia lúdica que envolva as crianças para se encantarem com as histórias desde cedo, bem como a dimensão da leitura para a sensibilização quanto à valorização humana, tendo em vista os direitos das crianças à leitura, à educação de qualidade e ao reconhecimento de sua cidadania. 


\section{Referências}

BRANDÃO, H.H. N.; MICHELETTI, G.(Coords.). Aprender e ensinar com textos didáticos e paradidáticos. Vol. 2. São Paulo: Cortez, 1997.

BRASIL. Ministério da Educação. Secretaria da Educação Básica. Diretrizes Curriculares Nacionais para a educaçáo infantil. Brasília: MEC, SEB, 2010.

BRASIL. Ministério da Educação. Conselho Nacional de Educação (2009). Câmara de Educação Básica. Resoluçáo no 5, de 17 de Dezembro de 2009. Fixa as Diretrizes Curriculares Nacionais para a Educação Infantil. Brasília: MEC, CNE, 2009.

BRASIL. Lei de Diretrizes e Bases da Educaçáo. Lei no 9.394/96, de 20 de dezembro de 1996.

BRASIL. Estatuto da Criança e do Adolescente. Lei Federal no 8069, de 13 de julho de 1990.

BRATNEY, S. M. Adivinha quanto eu te amo. $3^{\text {a }}$ ed. - São Paulo: Editora WMF Martins Fontes, 2011.

CANDAU, V.M.et al. Educaçáo em Direitos Humanos e formaçáo de professores (as). $1^{\text {a }}$ ed. Sáo Paulo: Cortez, 2013.

CANTÚ, A. Série Sentimentos. Campo Grande: Gráfica e Editora Alvorada, 2012.

COELHO, K.; MACHADO, M. A. A importância da leitura na Educaçáo Infantil: um estudo teórico. 2015. Disponível em: http://fapb.edu.br/media/ files/35/35_1941.pdf. Acesso em: 12 fev. 2018.

DELORY-MOMBERGER, C. Biografia e educação: figuras do indivíduoprojeto. Natal: EDUFRN; São Paulo: Paulus, 2006.

ESCOLA MUNICIPAL SULIVAN SILVESTRE DE OLIVEIRA CRIANÇA DO FUTURO. Projeto Político Pedagógico da TUMUNE KALIVONO. Campo Grande: Secretaria Municipal de Educação, 1999.

CENPEC; FUNDAÇÃO VOLKSWAGEN. Entre na roda. Leitura na escola e na comunidade. Volume 1- introdução - De livros, leituras e leitores. São Paulo, 2011.

JOSSO, M.Christine. Experiências de vida e formaçáo. Lisboa, Editora Educa, 1945. 
LAJOLO, M.; ZILBERMAN, R..Literatura infantil brasileira. História e história. 2a ed. São Paulo: Editora ática, 1985. Série Fundamentos.

LARROSA, J. Pedagogia profana. Danças, piruetas e mascaradas. Tradução de Alfredo Veiga-Neto. 5. Ed. 1. Reimpr. Belo Horizonte: Autêntica Editora, 2015.

MACIEL, L.T.L.; JOSE DA SILVA, G. Nem "Programa de Índio", nem "Presente de Grego". In: Revista Brasileira de História da Educaçáo, no. 19, p. 205-226, jan./abr. 2009. Disponível em: <http://www.rbhe.sbhe.org.br/index.php/rbhe/ article/download/84/92> Acesso em 02.mai. 2016.

OLIVEIRA, Z.de M.R. O trabalho do professor na Educaçáo Infantil. $2^{a}$ ed. Sáo Paulo: Biruta, 2014.

PEREIRA,E. de J.; FRAZÃO, G. C.; SANTOS, L. C. dos. Leitura infantil: o valor da leitura para a formação de futuros leitores. 2012. Disponível em: <http:// portaldeperiodicos.eci.ufmg.br/index.php/moci/article/viewFile/2162/135>. Acesso em: 12 fev. 2018.

PRETI D. (org) O discurso oral culto. In: Normas de Transcrição. 2a . ed. São Paulo: Humanitas Publicaçóes. FFLCH/USP, 1999. Projetos Paralelos. v. 2. 224p. Disponível em: <http://www.concordancia.letras.ufrj.br/index.php?option=com_ content\&view=article\&id=52\&Itemid=58>. Acesso em: 22 fev. 2017.

SANTOS, D. L. dos. Desenvolvimento moral na Educaçáo Infantil: o que pensam as educadoras. Mestrado em Psicologia. Programa de Pós-Graduação em Psicologia, Universidade Federal do Rio Grande do Sul, Porto Alegre, 2012.

SILVEIRA DE SOUZA, C.C. Educaçáo moral e personalidade: exercitando as virtudes na infância. Tese de Doutorado. Programa de Pós-Graduação em Educação, Universidade Federal do Rio de Janeiro, Rio de Janeiro, 2016.

SOLÉ, I. Estratégias de leitura. Porto Alegre: Artmed: 1998.

SOUZA, I. R. C. S. de; GARCIA, M.M. Ainda não sei ler e escrever: alunos indígenas e o suposto fracasso escolar. Educaçáo \& Realidade, Porto Alegre, v. 42, n. 1, p. 199-213 j/março, 2017. Disponível em: <http://dx.doi. org./10.1590/2175-623651362>. Acesso em: 6 de jul. 2017.

THIÉL, J. C. Educação \& Realidade, Porto Alegre, v. 38, n. 4, p. 1175-1189, out./dez.2013. Disponível em: <http:www.ufrgs.br/edu_realidade>. Acesso em: 7 jul. 2017.

Toda criança tem direitos. In: Vídeo Canal Belinha a Ovelhinha da Revista F C Digital. Disponívelem:<https://www.youtube.com/watch?v=wmNnzKOOuA0> Acesso em: 28 jul. 2021. 
VILAMAIOR, M. E. Rodas de leitura na primeira infância: formação de leitores e valores humanos em uma escola municipal de Campo Grande, MS. Dissertação (Mestrado) -Educação - Universidade Estadual de Mato Grosso do Sul, 2018. Campo Grande, MS: UEMS, 2018. 245p. Disponível em: <http://www.uems.br/assets/ uploads/cursos_pos/cf56c0d8020c416fb02f65f15e977953/teses_dissertacoes/1_cf5 6c0d8020c416fb02f65f15e977953_2018-11-08_08-23-49.pdf >. 